\title{
КУМУЛЯТИВНОЕ ОПРЕДЕЛЕНИЕ ДВУОКИСИ СЕРЫ И ФТОРИДОВ В АТМОСФЕРНОМ ВОЗДУХЕ
}

Колебание интенсивности эмиссии загрязнителей воздуха и неустойчивость погодных условий вызывают быстрое изменение концентраций загрязнителей атмосферного воздуха в точках наблюдения. Для получения полной картины о загрязненности воздуха требуются данные исследования в течение длительного времени с возможно большей частотой измерений. Однако считается, что многократное определение характеристик атмосферных загрязнений в нескольких стационарных точках (например в пяти точках около 40 раз) менее репрезентативно, чем однократное определение в 200 точках ['].

Представляется, что оптимальным решением было бы проведение анализа в большем количестве точек с определенной частотой измерений, но осуществление такого исследования трудоемко и большинству лабораториям не под силу.

Одной из возможностей, которая удовлетворяла бы указанным требованиям, получения обзорных данных о распределении загрязнителей воздуха и открытия источников загрязнений являются описанные в настоящей работе кумулятивные методы их определения. Полученные при кумулятивном определении данные о среднем распределении загрязнений в участке наблюдения представляют интерес и потому, что степень вредного влияния загрязнений зависит как от их объема, так и от длительности их действия.

Принцип кумулятивного определения загрязнителей воздуха состоит в том, что в точках наблюдения устанавливают образцы, которые абсорбируют из воздуха исследуемые вещества или же реагируют с ними. Количество абсорбированного вещества, или величина изменения образца при реакции, зависит как от времени экспонирования, так и от концентрации исследуемого вещества в воздухе. Кумулятивное определение примесей не дает данных об абсолютных концентрациях загрязнений воздуха, но представляет четкую картину относительного распределения этих веществ в изучаемом районе. Полученные таким путем обзорные данные, дают возможность определить районы нахождения источников загрязнений, правильно спланировать дальнейший ход и количество исследований. Экономичность кумулятивного метода позволяет определить загрязненность воздуха в нескольких (в ста и более) точках одновременно. Для получения сведений о распределении абсолютных концентраций примесей в изучаемом районе достаточно провести количественные изме- 
рения только в нескольких точках и распространить полученные данные сравнением и на другие точки кумулятивного определения. Таким образом, кумулятивное определение загрязнителей воздуха является полезным и легко применимым дополнением при исследовании санитарного состояния воздуха.

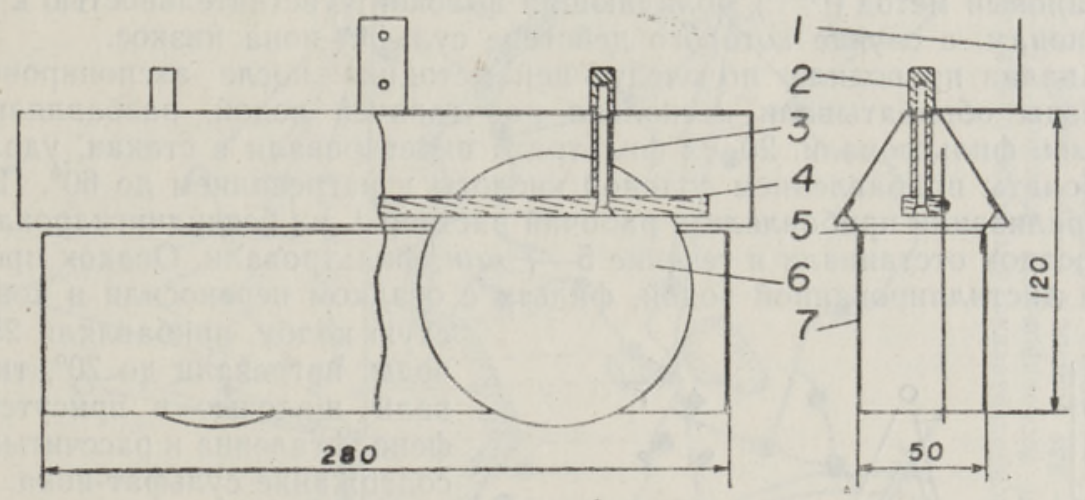

Рис. 1. Домик экспонирования образцов. 1 - консоль прикрепления домика, 2 - гайка, 3 - болт, 4 - стержень установки образцов, 5 - стержень крепления крыши, 6 - образец, 7 - корпус домика.

Для кумулятивного определения $\mathrm{SO}_{2}$ еще в 1932 году в Англии был применен метод $\mathrm{Pb}$-свечей $\left[{ }^{2}\right]$. В последние годы этот метод был усовершенствован и использовался во многих работах по изучению распространений $\mathrm{SO}_{2}$ в воздушном пространстве населенных мест [3-5]. Нами для этой же цели было использовано изменение скорости ржавления стальных образцов $\left.{ }^{6}\right]$.

Первоначальные опыты по кумулятивному улавливанию фторидов проводились с использованием растений, в частности эпифитов $[7,8]$. В настоящее время нанболее распространено применение пропитанных известью фильтровальных бумаг [9]. Абсорбированный ион фтора определяют колориметрически [10] или при помощи селективных электродов $\left[{ }^{11,12}\right]$.

\section{Әкспериментальная часть}

Методика. Изучалась возможность одновременного накопления $\mathrm{SO}_{2}$ и фторидов едиными образцами. В качестве последних служили диски фильтровальной бумаги, пропитанные $25 \%$-ным водным раствором $\mathrm{K}_{2} \mathrm{CO}_{3}$ с $10 \%$-ным содержанием глицерина. Глицерин использовался в качестве гигроскопического вещества для сохранения влажности образцов.

Способ пропитывания фильтровальных бумаг должен обеспечить по качеству возможно однородные образцы. Наилучшие результаты получены погружением дисков из фильтровальной бумаги в раствор и удалением избыточного раствора резиновым валиком под определенным давлением. Образцы сушились в термостате при $70^{\circ} \mathrm{C}$. Содержание $\mathrm{K}_{2} \mathrm{CO}_{3}$ в одном образце (диаметр 12 см) равнялось 560 мг \pm 30 мг.

Образцы помещали в установленные на высоте $4 \mu$ от земли жестяные домики (рис. 1), которые защищали их от разрушающего действия погоды и имели свободный доступ воздуха.

Определение сульфатов и фторидов из одной и той же пробы требует таких методов анализа, которые взаимоисключали бы мешающее влияние друг на друга ионов при их определении. Концентрации сульфатов 
при сравнении с фторидами в образцах обычно высоки и поэтому для их определения не требуется особо чувствительного метода анализа. Нами использован метод осаждения сульфат-иона с бензидингидрохлоридом $\left.{ }^{13}\right]$. Из осадка определяли сульфат-ион, а из фильтрата фторидион. Для определения фторидов использовали La-ализариновый комплексановый метод [14-16], обладающий высокой чувствительностью к фторид-ионам, в случае которого действие сульфат-иона низкое.

Анализ проводили по следующей методике: после экспонирования образцы обрабатывали несколько раз горячей водой, разбавляли до 100 мл, фильтровали. 20 мл фильтрата пипетировали в стакан, удаляли карбонаты прибавлением соляной кислоты и нагреванием до 60. После нейтрализации прибавляли в рабочий раствор 1 мл бензидингидрохлорида, осадок отстаивали в течение 5-7 мин, фильтровали. Осадок промывали дистиллированной водой, фильтр с осадком переносили в кониче-

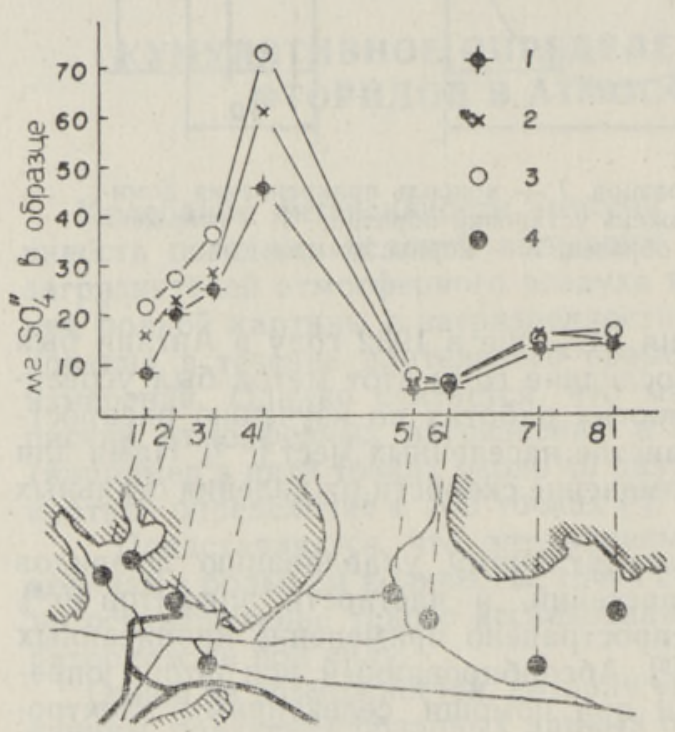

Рис. 2. Распространение $\mathrm{SO}_{2}$ В промышленном районе. Время экспонирования образцов: 1 две недели, 2 - три недели, 3 - четыре недели; 4 - точка наблюдения.

вается. При необходимости фильтруется. воды, нагревали до $70^{\circ}$, титровали щелочью в присутствии фенолфталеина и рассчитывали содержание сульфат-иона.

При определении фторидионов в 25 мл мерную колбу пипетировали 12,5 мл La-ализаринового реагента и в зависимости от содержания фторидов добавляли 0,5-12,5 мл фильтрата, полученного после осаждения сульфат-ионов. По соляной кислоте $\mathrm{pH}$ равнялось 4,3 . Спектрофотометрически определяли содержание фторидионов при $\lambda=618 \mathrm{mм}$.

Применяемые реактивы. 1. Раствор бензидингидрохлорида. Кашеобразная смесь, приготовленная из 40 г бензидина и 40 мл дистиллированной воды, переносится в 1-литровую мерную колбу, прибавляется $50 \mathrm{M} \mathrm{HCl}(d=1,19)$, заполняется водой до метки, взбалты-

2. Раствор лантан-ализаринового комплексана (La-AC) [16]. 0,04 z ализаринового комплексана $\left[{ }^{17}\right]$ растворяется в минимальном количестве 1 н $\mathrm{NaOH}$, а 0,0163 г $\mathrm{La}_{2} \mathrm{O}_{3}$ растворяется в минимальном количестве $1 \mathrm{H}$ $\mathrm{HNO}_{3}$, прибавляется 4 мл буферного раствора и 330 мл ацетона. Полученный раствор разбавляется до 500 мл дистиллированной водой. При хранении в лабораторных условиях реактив стабилен до 1 месяца.

Полевые наблюдения. Описанную методику использовали при изучении относительного распределения двуокиси серы и фтористых соединений в воздушном бассейне г. Таллина. Для этого в 29 точках наблюдения было установлено по 4 абсорбирующих образца и через каждую неделю один из них (во всех точках) отбирался для анализа.

Данные о содержании сульфат-иона в образцах, экспонированных ог 2 до 4 недель в одном из промышленных районов представлены на рис. 2, откуда видно, что в точке 4 имеется источник сернистых соединений, 

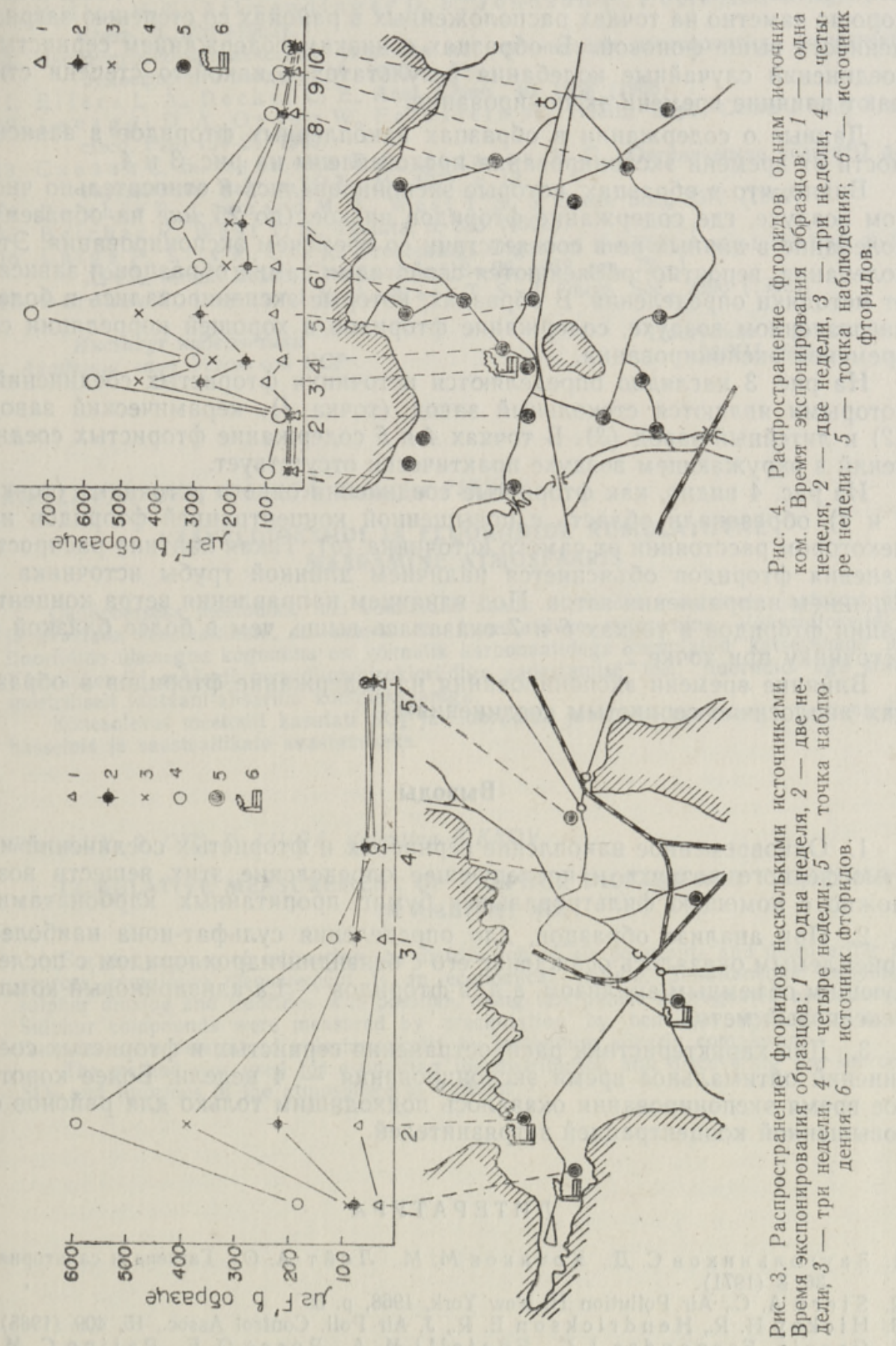
распространяющий влияние и на точки 1,2 и 3. В области точек 7 и 8 также источники сернистых соединений, но более слабые. Влияние времени экспонирования на содержание сернистых соединений в образцах, хорошо заметно на точках расположенных в районах со степенью загрязненности выше фоновой. В образцах с низким содержанием сернистых соединений случайные колебания результатов в какой-то степени стирают влияние времени экспонирования.

Данные о содержании в образцах накопленных фторидов в зависимости от времени экспонирования представлены на рис. 3 и 4 .

Видно, что в образцах, которые экспонировались в относительно чистом воздухе, где содержание фторидов низкое (до 25 мкг на образец), колебание в данных не в соответствии со временем экспонирования. Эти колебания, вероятно, объясняются свойствами самих образцов и зависят от методики определения. В образцах, которые экспонировались в более загрязненном воздухе, содержание фторидов в хорошей корреляции со временем экспонирования.

На рис. 3 наглядно определяются источники фтористых соединений, которыми являются стекольный завод (точка 1), керамический завод (2) и литейный завод (3). В точках 4 и 5 содержание фтористых соединений в окружающем воздухе практически отсутствует.

Из рис. 4 видно, как фтористые соединения одного источника (точки 3 и 4) образовали область с повышенной концентрацией фторидов на некотором расстоянии от самого источника (5). Такая картина распространения фторидов объясняется наличием длинной трубы источника и влиянием направления ветра. Под влиянием направления ветра концентрация фторидов в точках 6 и 7 оказалась выше, чем в более близкой к источнику при точке 2.

Влияние времени экспонирования на содержание фторидов в образцах аналогично сернистым соединениям.

\section{Выводы}

1. Одновременное накопление сернистых и фтористых соединений из атмосферного воздуха и последующее определение этих веществ возможно с помощью фильтровальных бумаг пропитанных карбонатами.

2. При анализе образцов, для определения сульфат-иона наиболее приемлемым оказалось осаждение его с бензидингидрохлоридом с последующим объемным анализом, а для фторидов - La-ализариновый комплексановый метод.

3. Для характеристики распространения сернистых и фтористых соединений оптимальное время экспонирования - 4 недели. Более короткое время экспонирования оказалось подходящим только для районов с повышенной концентрацией загрязнителей.

\section{ЛИ Т Е Р А Т Р А}

1. З аугольников С. Д., Кочанов М. М., Лойт А. О., Гигиена и санитария, 36,8 (1971).

2. Stern A. C., Air Pollution II. New York, 1968, p. 55.

3. Hickey H. R., Hendricks on E. R., J. Air Poll. Control Assoc., 15, 409 (1965),

4. Gracia-Fernandez J. C., Enatelli M. A., Roses O. E., Patino C. M., Proceedings of the Second Clean Air Congress. New York, 1971, p. 9.

5. McAdic H. E., J ones H. M., ibid., p. 70.

6. Луй га П., Ли й в Р., Т а м м и ст е П., Изв. АН Эст. ССР, Хим. Геол., 21, 295 (1972). 
7. M a c Intire W. H., Hard in L. J., Hester W., Ind. Eng. Chem., 44, 1365 (1952).

8. W a nder I. W., Eng. Progr. Univ. Florida, 10, Bull. 83, 14 (1956).

9. Miller V. L., All mendinger D. F., Johnson F., Polley D., J. Agr. Food Chem., 1, 526 (1953).

10. Инструктивно-методические указания по организации исследования загрязнения атмосферного воздуха, М., 1963, с. 52.

11. Elfers L. A., Decker C. E., Anal. Chem., 40, 1658 (1968).

12. Levaggi D. A., O y ung W., Feldstein M., Health Dept. Confer., San Francisco, Feb. 19-21, 1969.

13. С а в в ин С. Б., Аким ов а Т. Г., Д едков а В. П., Органические реагенты для определения $\mathrm{Ba}^{2+}$ и $\mathrm{SO}_{4}{ }^{2-}$. М., 1971, с. 13.

14. Belcher R., Le on a rd M. A., W est T. S., J. Chem. Soc., 3577 (1959).

15. Belcher R., We st T. S., Talanta, 8, 853 (1961).

16. Lu iga P., Li i v R., Ott R., Proceedings Digest of the 65th Annual Meeting of the APCA, Miami Beach, Florida, June $18-22,1972$, rep. $72-1$.

17. Belcher R., Le on ard M. A., West T. S., J. Chem. Soc., 2390 (1958).

\author{
Институт кибернетики \\ Академии наук Эстонской ССР
}

Поступила в редакцию 26/XII 1972

\section{Reet LIIV, R. OTT, P. LUIGA, Valentina PIKKOV}

\section{VÄ̊RELDIOKSIIDI JA FLUORIIDIDE KUMULATIIVNE MÄRAMINE ATMOSFÄÄRIS}

Okonoomseks meetodiks, mis võimaldab saada ülevaadet saastainete jaotusest õhus ja avastada saasteallikaid, on saastainete kumulatiivne määramine. Vääveldioksiidi ja fluoriidide üheaegne kogumine on võimalik karbonaatidega immutatud katsekehade abil. Väävliühendid määrati bensidiinhüdrokloriidiga sadestamise teel, fluoriidid aga kolorimeetriliselt lantaani-alisariini kompleksaaniga.

Kōnesolevat meetodit kasutati $\mathrm{SO}_{2}$ ja fluoriidide jaotumise uurimiseks Tallinna ôhubasseinis ja saasteallikate avastamiseks.

Reet LIIV, R. OTT, P. LUIGA, Valentina PIKKOV

\section{CUMULATIVE MEASUREMENT OF SULPHUR DIOXIDE AND FLUORIDES IN AMBIENT AIR}

For the purpose of estimating the distribution of air pollutants and discovering their sources, cumulative measurement is an economical method. Simultaneous trapping of sulphur dioxide and fluorides was possible, using test panels impregnated by carbonates. Sulphur compounds were measured by precipitation by benzidine hydrochloride, and fluorides were determined colorimetrically by lanthanum alizarin complexane.

The method was used for estimating the distribution and discovering the sources of $\mathrm{SO}_{2}$ and fluorides in the atmosphere of Tallinn. 